\title{
EL HOMBRE DE LA MULTITUD Y EL PINTOR DE LA VIDA MODERNA: LA INFLUENCIA DE EDGAR ALLAN POE EN LA CONSTRUCCIÓN DEL CONCEPTO DE MODERNIDAD DE BAUDELAIRE
}

\author{
Francisco Pizarro Obaid \\ Universidad Diego Portales \\ francisco.pizarro@udp.cl
}

RESUMEN / ABSTRACT

El siglo XIX dio lugar a nuevas formas de subjetividad metropolitana que tuvieron en el cuento "El hombre de la multitud", de Edgar Allan Poe, un tratamiento excepcional. Es innegable la relevancia de este relato al interior de su obra, así como su aporte al desarrollo del género narrativo. Sin embargo, el cuento de Poe puede ser considerado, a su vez, como una fuente de notable influencia en la redefinición del concepto de modernidad que Baudelaire plasmará en su obra "El pintor de la vida moderna". Al examinar el personaje anónimo de "El hombre de la multitud" y la singularidad del $S r$. $G$, pintor que da fundamento a la crítica de la tradición pictórica de costumbres, quedará en evidencia como los principales argumentos de Baudelaire sobre el arte y las nuevas formas de habitar la ciudad moderna encuentran en el relato de Poe una significativa fuente de inspiración.

Palabras clave: Poe, Baudelaire, multitud, arte, modernidad.

The $19^{\text {th }}$ century gave rise to new forms of metropolitan subjectivity with an exceptional treatment in Edgar Allan Poe's tale "The Man of the Crowd". The relevance of this short story into his work is undeniable, as well as its contribution to the development of the narrative genre. However, Poe's story can be considered as a source of considerable influence in the redefinition of the concept of modernity, that Baudelaire will express in his work "The Painter of Modern Life". In examining the anonymous character of "The Man of the Crowd" and the singularity of $\mathrm{Mr}$. G, the painter who gives substance to the criticism of the pictorial tradition 
of customs, it grows evident how Baudelaire's main arguments on art and the new ways of life in the modern city find in Poe's short story a significant source of inspiration.

Key words: Poe, Baudelaire, crowd, art, modernity.

\section{INTRODUCCIÓN}

Los comentarios críticos y las interpretaciones sobre el cuento "El hombre de la multitud", de Edgar Allan Poe han sido diversos y heterogéneos. Al considerar la dimensión psicológica involucrada en el relato, Marie Bonaparte destacó la incidencia de procesos inconscientes, tanto en la definición del narrador, como en la relación que sostendrá con la enigmática figura de su antagonista. Su obra, Edgar Poe, étude psychanalytique, escrito tributario de los postulados de Sigmund Freud ${ }^{1}$, marcará una vía interpretativa fundamental al suponer que "Las obras literarias y artísticas de los hombres revelan los aspectos más íntimos de su psique ..." (7).

Otros autores ampliarán la gama de proceso psíquicos involucrados en su trama, al consignar que mediante la exposición del inquietante periplo emprendido por el protagonista en la ciudad, Poe habría dado a la problemática del doble, tal vez, "el tratamiento más ingenioso que jamás tuvo" (Quinn, The French 229) o, al sugerir que la historia marcaría un giro en el tratamiento de la criminalidad, bajo la fórmula de "una especulación metafísica sobre el crimen y el carácter humano" (Yoswick 237). Werner llegaría incluso a proponer que la exploración emprendida en la ficción representaría "no solo una cara individual, sino que también, el interior privado, la ciudad, el mundo, incluso el cosmos" (p. XI).

En otra vertiente interpretativa, el eje fundamental, que haría de esta narración una pieza excepcional, sería el problema de la observación y el razonamiento (Kennedy 185; Sweeney 4). Para Brand, el cuento constituiría un punto de referencia en la progresiva renovación del método de investigación

En el prólogo a la obra de Marie Bonaparte "Edgar Poe. Étude psychanalytique", Freud definirá a Poe como un "gran poeta de genio patológico" (229). Celebrará el escrito de su discípula y amiga, pues "Merced a su trabajo interpretativo se comprende ahora cuántos de los caracteres de su obra están condicionados por la peculiaridad del hombre, pero se averigua también que esta última es la sedimentación de intensas ligazones afectivas y vivencias dolorosas de su primera juventud" (229). 
que encontrará su consolidación en la figura de Dupin, paradigma de la detección. En este sentido, el relato sobre la multitud "puede haber llevado a Poe a desarrollar el género del cuento de detectives" (79). Sin embargo, la discusión sobre el valor y la significación de la obra tendrá otros alcances.

Benjamin ya había puntualizado en sus reflexiones sobre Paris y el siglo XIX que "las primeras contribuciones a la fisionomía de la multitud se encuentran en Engels y en Poe" (45), pero advertía, al mismo tiempo, que mediante este escrito "Poe fijó para siempre el caso del flâneur que se separa por completo del tipo del paseante filosófico y que adquiere los rasgos del hombre lobo que merodea inquieto en la selva social" (423). En esta perspectiva, el texto enunciaría "una cierta «sensibilidad» específicamente metropolitana" (Cunningham 44) y tematizaría una novedosa forma de inscripción en el tiempo y el espacio de las emergentes ciudades modernas de comienzos del siglo XIX (Tester 1). A su vez, el relato incorporaría problemáticas socioculturales bajo el signo de la ficción (Levine 16; Byer 221; Elbert 16).

Entre las diversas reflexiones que promovió "El hombre de la multitud" resulta, asimismo, posible constatar la inequívoca presencia del relato de Poe en la obra "Le peintre de la vie moderne" [El pintor de la vida moderna], texto en el cual Baudelaire ofrecerá un análisis crítico de la pintura de costumbres y desarrollará una definición paradigmática de lo que denominará la modernidad ${ }^{2}$. Aunque la única alusión explícita a Poe sea sucinta y, en apariencia, anecdótica, -“¿Recuerdan un cuadro (¡en verdad es un cuadro!) escrito por la más poderosa pluma de esta época y que tiene por título El hombre de la multitud?" (Baudelaire, El pintor 61)- el análisis pormenorizado de los dos escritos mostrará la referencia sistemática de Baudelaire a los elementos que estructuran y dan fundamento al cuento de Poe.

A partir de este entrecruzamiento textual, es posible considerar al relato de Poe "El hombre de la multitud" como un antecedente ineludible en la

2 Para Berman las reflexiones plasmadas por Baudelaire en sus escritos "Del Heroísmo de la vida moderna" (1846) y "El pintor de la vida moderna" (1863) "fijaron el programa de todo un siglo de arte y pensamiento" (130). 
comprensión del tratamiento que Baudelaire dará a las figuras del artista y el flâneur ${ }^{3}$ en su proyecto de reconceptualizar la modernidad.

\section{POE Y LAS VERSIONES DE LA MULTITUD}

En contraste con la variada y exhaustiva exploración de las relaciones amorosas, familiares, fraternales o amistosas que Poe desarrolló en obras como "Berenice", "Morella" "Ligeia", "La caída de la casa Uscher" o "William Wilson", la figura de la multitud no evidencia, en una primera etapa, una recurrencia sistemática en sus relatos. Mediante un tratamiento esporádico y disímil, la multitud y los espacios urbanos son introducidos, inicialmente, bajo el signo de lo pretérito y lo exótico o a través de escenarios donde se despliegan hazañas o eventos excepcionales.

Esta modalidad de construcción puede ser constatada en la sobrenatural transformación del rey Antíoco Epifanes, quien en medio de la conmoción y la efervescencia de la muchedumbre, de la chusma, del tumulto, muta en la excepcional bestia denominada camaleopardo (Poe, Cuatro bestias 869); o en la historia de la "muerte roja" que se cierne sobre el reino del Príncipe Próspero y que lleva a un grupo de mil elegidos a refugiarse en las abadías fortificadas; inevitablemente la lujuria y la voluptuosidad se transformarán en sangre y muerte, tras la visita del enmascarado que sorteará los seguros límites del encierro (Poe, La máscara 171). En la misma perspectiva, resulta instructiva la experiencia que vivió Augustus Bedloe, paciente del mesmerista Dr. Templeton, quien en su habitual caminata por las montañas de Charlottesville se verá súbitamente inmerso en una convulsionada ciudad oriental en pie de guerra. Al intentar distinguir si se trataba de una experiencia onírica o real, el Dr. Templeton exhibirá una acuarela fechada en 1780 que retrataba a un amigo ya muerto. La imagen de $M r$. Oldeb, compañero de su adolescencia, coincidía con la del joven Bedloe (Poe, Un cuento 179).

3 La figura del flaneur -que en su acepción más coloquial alude al paseante, al callejero- emerge en este nuevo escenario urbano, para hacer de la flânerie "una forma de mirar, observar (la gente, los tipos sociales, los contextos y las constelaciones sociales); una forma de leer la ciudad y su población (sus imágenes espaciales, su arquitectura, sus configuraciones humanas) y una forma de leer textos escritos" (Frisby 42). 
La posible función que cumple la figura de la multitud en los relatos precedentes puede ser comprendida bajo los principios enunciados en la obra The philosophy of composition [La filosofia de la composición], donde Poe afirmaba que toda creación tiene por objetivo primordial la producción de un efecto. Ante tal desafío, el proceso de composición se inicia con la identificación de una novedad y un efecto vívido, para luego decidir si la mejor forma de conseguirlo sería mediante un incidente o un tono "ya sea por incidentes ordinarios y un tono peculiar, o a la inversa, o por la peculiaridad tanto del incidente y del tono" (Poe, La filosofía 163). De este modo, podría considerarse al colectivo como un recurso que tiene por fin el desencadenamiento de un efecto ominoso, angustioso o terrorífico, bajo un juego sistemático de contrastes entre la figura y el fondo o un medio para la creación de una atmósfera singular donde transcurre la interacción de los personajes. Las dimensiones de la observación, el movimiento y la temporalidad, aunque sugerentes y provocadoras en aquellos relatos, no introducen una reformulación de lo individual y lo colectivo.

El tratamiento de los elementos que tendrán como meta la creación de un efecto, serán novedosos en "El hombre de la multitud", ya que su composición, además de la producción de efectos inquietantes, enunciará nuevas formas de relación a la metrópolis y la multitud.

\section{POE Y EL NUEVO HOMBRE DE LA MULTITUD}

El relato "El hombre de la multitud" resulta ser un cuento inusual en el universo de Poe. La ausencia de nombres y el gran dinamismo de sus personajes contrastan con los recurrentes escenarios, sofocantes y claustrofóbicos, de sus protagonistas más notables (Frank y Magistrale 218; Sova, 105). Sin embargo, su carácter excepcional no se agota en esta particularidad, ya que su trama involucra, a su vez, un inédito tratamiento de las relaciones contingentes que el narrador establece con la ciudad y sus habitantes, así como también un predominio de la mirada y la lectura del paisaje urbano (Hayes 445).

$\mathrm{Al}$ iniciar la historia de sus últimas experiencias, el narrador ofrecerá una sintética pero profunda reflexión sobre lo humano. Tras exponer algunas figuras de lo inefable, advertirá que, así como hay libros que no se dejan leer, "Hay ciertos secretos que no se dejan expresar" (Poe, El hombre 247), para luego agregar que los "misterios que no permiten que se los revele" (247) sumergen al hombre en la agonía, la desesperación y la angustia. Por 
ello, en ocasiones "la conciencia del hombre soporta una carga tan pesada de horror que sólo puede arrojarla a la tumba. Y así la esencia de todo crimen queda inexpresada" (247).

El relato transcurre en las calles y avenidas de Londres, uno de los prototipos de la gran ciudad de su época. La escena inaugural muestra al narrador sentado en un café junto a un gran ventanal en el transcurso de un atardecer otoñal. Tras varios meses de enfermedad, su estado es el de la convalecencia (247). Pese a todo, primaban en él la apetencia y la irrupción de renovadas fuerzas en las que "se desvanecen los vapores de la visión interior... y el intelecto electrizado sobrepasa su nivel cotidiano ... Sentía un interés sereno, pero inquisitivo, hacia todo lo que me rodeaba [precisará]" (247).

La tarde había transcurrido entre su cigarro, el periódico, los anuncios o "mirando hacia la calle a través de los cristales velados por el humo" (247). La densa multitud que recorría las calles se volvía más agitada y numerosa cuando los primeros destellos de la luminaria insinuaban el anochecer; de pronto, confesará, "el tumultuoso mar de cabezas humanas me llenó de una emoción deliciosamente nueva. Terminé por despreocuparme de lo que ocurría adentro y me absorbí en la contemplación de la escena exterior" (248).

La masa, que en una primera aproximación sugería el análisis de sus relaciones colectivas, será examinada privilegiando detalles tales como "figuras, vestimentas, apariencias, actitudes, rostros y expresiones" (248). Con minuciosidad taxonómica, se establecerán clases, tipos y subtipos. El listado expuesto de manera jerárquica incluía: "decentes", "empleados superiores", "empleados menores", "carteristas elegantes", "jugadores profesionales". Algo distintos, pero en la misma categoría, se encontraban: "caballeros que viven de su ingenio" entre los que destacan los dandys y los militares. Descendiendo en la escala social, se hallaban: "buhoneros judíos", "mendigos callejeros profesionales", "inválidos", "modestas jóvenes", "rameras", "leprosas harapientas", "niña de formas apenas núbiles", "borrachos", "pasteleros", "mozos de cordel", "acarreadores de carbón", "deshollinadores, "organilleros", "exhibidores de monos amaestrados", "cantores callejeros", "artesanos desastrados", "obreros" (248- 250).

Su particular estado de ánimo promovía en él la extraña sensación de ser "capaz de leer la historia de muchos años en el breve intervalo de una mirada" (251). De pronto, la multitud lo confrontaría con un momento hipnótico y asombroso. En un instante, advertirá, "se me hizo visible un rostro (el de un anciano decrépito de unos sesenta y cinco o setenta años) que detuvo y absorbió al punto toda mi atención, a causa de la absoluta singularidad de 
su expresión. Jamás había visto nada que se pareciese remotamente a esa expresión" (251).

$\mathrm{Al}$ intentar definir lo que había experimentado acudía a su pensamiento la figura del demonio. Comenzó a pensar que aquel viejo era portador de una "enorme capacidad mental, cautela, penuria, avaricia, frialdad, malicia, sed de sangre, triunfo, alborozo, terror excesivo, y de intensa, suprema desesperación. "iQué extraordinaria historia está escrita en ese pecho!»" (251). Los reflejos de un farol revelaron dos elementos que encendieron su curiosidad. Un diamante y un puñal se asomaron en el abrigo del viejo y, ante tal revelación, se impuso la imperiosa necesidad de alcanzarlo, a como diera lugar. El apremio por descifrar aquellos signos lo impulsó a iniciar una cautelosa y sistemática persecución del sujeto.

Inmerso en la ciudad se aventuró en el seguimiento de la enigmática figura. En su trayecto recorrió la misma cartografía social establecida en la seguridad del café. Franqueó, incluso, los límites seguros de la urbe para adentrarse en la periferia donde se imponían la pobreza y la criminalidad.

Tras la segunda noche de persecución, cansado y abatido, enfrentó finalmente al viejo. Por un instante, su mirada alcanzó su rostro. No encontró respuesta alguna, ya que el errante, con desdén, prosiguió su camino. La búsqueda había terminado y la conclusión sería avasalladora:

Este viejo -dije por fin- representa el arquetipo y el genio del profundo crimen. Se niega a estar solo. Es el hombre de la multitud. Sería vano seguirlo, pues nada más aprenderé sobre él y sus acciones. El peor corazón del mundo es un libro más repelente que el Hortulus Animae, y quizá sea una de las grandes mercedes de Dios el que er lässt sich nicht lesen (254).

Este breve, pero sugerente relato, será un nuevo punto de encuentro entre Poe y Baudelaire, quien tomará cada una de las piezas que componen el cuento para sustentar su reflexión sobre el problema del arte, la ciudad y la modernidad, dando cuenta de la presencia inequívoca de Poe en su argumentación.

\section{BAUDELAIRE Y POE: EL PINTOR DE COSTUMBRES Y EL HOMBRE EN LA MULTITUD}

Las relaciones que Baudelaire estableció entre la imagen y la obra de Poe estuvieron marcadas por la devoción, la fascinación y la productividad. Tras 
la revisión de las obras críticas consagradas al examen de su legado llegará a calificar a Rufus Griswold - primer biógrafo y testamentario del poeta norteamericano- como un difamador, un "vampiro-pedagogo" (Baudelaire, Edgar 48). Con tono sarcástico se preguntará si "¿Acaso no existe en América una disposición que prohíba la entrada de perros a los cementerios?" (Baudelaire, Edgar 48).

No ahorrará elogios en la defensa de Poe y lo definirá como el "cerebro privilegiado de los Estados Unidos ... no es específicamente un poeta o un novelista: es poeta, novelista y filósofo. Lleva en sí la doble naturaleza del iluminado y del sabio" (Baudelaire, Edgar 21). Su patria, en cambio, solo sería un "país gigantesco y niño, lógicamente celoso del viejo continente" (Baudelaire, Edgar 49). Bajo estas consideraciones, Baudelaire se transformaría en el traductor de su obra a la lengua francesa y en su más ferviente difusor en Francia y Europa (Françon 841; Quinn, The profundities 3; Richard 9).

En un mimetismo estremecedor, que evocaba los efectos buscados por Poe en sus relatos, recordaría las primeras impresiones que le provocó el poeta: "Encontraba, créame si quiere, poemas y novedades respecto de las cuales había tenido un pensamiento vago y confuso, desordenado y que Poe había sabido combinar y llevar a la perfección" (Baudelaire, Lettres 176). Al develar la motivación que lo llevó a la minuciosa y paciente traducción de sus escritos, ofrecerá una respuesta similar, pero aún más precisa: "Porque él se parecía a mí [confesará]. La primera vez que abrí un libro de él, vi con espanto y arrebato, no solamente temas soñados por mí, sino que FRASES pensadas por mí y escritas por él, veinte años antes" (Baudelaire, Lettres 362). Más allá de la identificación o el mimetismo con su admirado artista, Baudelaire extraerá una serie de principios y fundamentos de la obra de Poe que participarán de sus reflexiones sobre el arte. No se trata, por tanto, de una simbiosis, sino de "la coincidencia de una serie de elementos poetológicos y estilísticos que permiten prolongar esa afinidad incluso más allá de lo percibido por el propio Baudelaire" (Ponzi 95).

La actividad poética y literaria condujo tempranamente a Baudelaire al campo del arte, donde se transformó en un crítico acérrimo de la idealización de la vida antigua y la tradición. En el capítulo final de su obra Salon de 1846, titulado "De l'héroïsme de la vie moderne" [Del heroísmo de la vida moderna], proponía buscar el lado épico de la vida moderna (Baudelaire, Salon 194), con el fin de probar que su época "no es menos fecunda que las antiguas en temas sublimes... puesto que todos los siglos y todos los pueblos han tenido su belleza, nosotros tenemos inevitablemente la nuestra" 
(194). De este modo, negaba la existencia de una belleza perpetua o ideal para promover como hipótesis central que "todas las bellezas contienen, como todos los fenómenos posibles, algo de eterno y algo de transitorio - de absoluto y particular" (194).

El estudio de la pintura de costumbres ${ }^{4}$ del presente le permitirá consolidar dichas hipótesis y promover una nueva forma de comprender la modernidad. $\mathrm{Su}$ objetivo será establecer una "teoría racional e histórica de lo bello, en oposición con la teoría de la belleza única y absoluta" (Baudelaire, El pintor 54). En esa empresa, la impronta de Poe se revelará como fundamental.

\section{EL SR. G Y LA REDEFINICIÓN DE LO MODERNO}

El análisis de las peculiaridades de la pintura de costumbres del presente, expuesta en el texto "El pintor de la vida moderna", estará basada en la obra de un artista $^{5}$ en cuya producción está ausente la firma; el pintor -quien vive con pudor y enfado todo intento por develar su identidad- receloso de su intimidad solicitará al poeta la supresión de toda referencia a su nombre y exigirá que se hable de la obra de un anónimo. Ante tal requerimiento, Baudelaire invitará a sus lectores a hacer como si el pintor -a quien denominará $S$ r. $G$ no existiera y propondrá ocuparse solo de sus dibujos y acuarelas. Incluso, advertirá, "para tranquilizar completamente mi consciencia, supondremos que todo lo que tengo que decir de su naturaleza, tan curiosa y misteriosamente deslumbrante, es, más o menos, justamente sugerido por las obras en cuestión; pura hipótesis poética, conjetura, trabajo de la imaginación (59).

Al igual que en el relato de Poe, y más allá de las exigencias del pintor, el anonimato es una condición para el desarrollo de una trama en la que confluyen la realidad y la ficción. El $S r$. $G$ es descrito como un "gran enamorado de la multitud y del incógnito" (58); como un artista viajero y cosmopolita, en definitiva, se trataría de un hombre de mundo:

\footnotetext{
$4 \quad$ “... el genio de un artista pintor de costumbres es un genio de naturaleza mixta, es decir en el que participa una gran parte del espíritu literario... Algunas veces es poeta; más a menudo se aproxima al novelista o al moralista; es el pintor de la circunstancia y de todo lo que sugiere de eterno" (Baudelaire, El pintor 57).

Se trata del acuarelista y dibujante, Ernest Adolphe Hyacinthe Constantin, más conocido como Constantin Guys (1802- 1892).
} 
Entiendan aquí, se lo ruego, la palabra artista en un sentido muy restringido, y la palabra hombre de mundo en un sentido muy amplio. Hombre de mundo, es decir hombre del mundo entero, hombre que comprende el mundo y las razones misteriosas y legítimas de todas sus costumbres; artista, es decir, especialista, hombre apegado a su paleta como el siervo a la gleba. Al Sr. G. no le gusta ser llamado artista ... Se interesa por el mundo entero; quiere saber, comprender, apreciar todo lo que pasa en la superficie de nuestra esfera" (60).

La clave de su genio está para Baudelaire en su curiosidad, la cual "ha devenido una pasión fatal, jirresistible!” (61); en su espiritualidad, la que puede ser descrita como un estado de permanente convalecencia (61), rasgo esencial para comprender su carácter. Esta condición puede ser descrita como un retorno a la infancia, ya que "el convaleciente goza en el más alto grado, como el niño, de la facultad de interesarse vivamente en las cosas, incluso en las más triviales en apariencia" (62). Al acentuar esta posición, podría incluso llegar a denominársela congestión.

Curiosidad y convalecencia refieren directamente al personaje de Poe y apuntan al regocijo que experimenta el personaje en su observación a través del ventanal del café. Tras esta caracterización se impone la tarea de precisar el rasgo distintivo, el estatuto de su admirado pintor.

Ante las imprecisiones que podría conllevar la categoría de artista, y tras refutar la inclinación a identificarlo con un filósofo ${ }^{6} \mathrm{o}$ con un $d a n d y^{7}$, el

6 "Lo decoraría con el nombre de filósofo, al que tiene derecho por más de una razón, si su amor excesivo por las cosas visibles, tangibles, condensadas al estado plástico, no le inspirara una cierta repugnancia hacia aquellas que forman el reino intangible del metafísico" (Baudelaire, El pintor 64).

"Estos seres no tienen otra profesión que la de cultivar la idea de lo bello en su persona, satisfacer sus pasiones, sentir y pensar. Poseen así, a su antojo y en gran medida, el tiempo y el dinero, sin los cuales la fantasía, reducida al estado de sueño pasajero, apenas puede traducirse en acción ... sin el ocio y el dinero, el amor no puede ser más que una orgía de plebeyo o el cumplimiento de un deber conyugal ... El dandismo no es siquiera, como muchas personas poco reflexivas parecen creer, un gusto desmesurado por el vestido y por la elegancia material. Esas cosas no son para el perfecto dandi más que un símbolo de la superioridad aristocrática de su espíritu. Igualmente, a sus ojos, prendados ante todo de la distinción, la perfección del vestido consiste en la simplicidad absoluta, que es en efecto la mejor manera de distinguirse. Es, ante todo, la necesidad ardiente de hacerse una originalidad, contenida en los límites exteriores de las conveniencias. Es una especie de culto de sí mismo... Es el placer de sorprender y la satisfacción orgullosa de no sorprenderse nunca... En ciertos aspectos, el dandismo limita con el espiritualismo y el estoicismo. Pero un dandi nunca puede ser un 
Sr. G será calificado como un hombre de mundo (60), un hombre-niño (63), un eterno convaleciente (63). Mediante estas designaciones, Baudelaire no solo ha hecho surgir el rasgo definitivo del pintor, sino que ha invocado y personificado al narrador de Poe, dando lugar a la emergencia de una nueva forma de subjetividad, que hace de la multitud su fundamento. Como si se tratase de una relectura del cuento, su posición frente al mundo, será detallada por Baudelaire, para consignar que:

La multitud es su dominio, como el aire es el del pájaro. Su pasión y su profesión, es desposar la multitud. Para el perfecto paseante [flâneur], para el observador apasionado, es un inmenso goce fijar domicilio en el conjunto, en lo ondulante, en el movimiento, en lo fugitivo y lo infinito. Estar fuera de casa, y por tanto, sentirse en casa en todas partes; ver el mundo, estar en el centro del mundo y permanecer oculto en el mundo, tales son algunos de los mínimos placeres de esos espíritus independientes, apasionados, imparciales, que la lengua solo puede definir torpemente (64).

La caracterización será elocuente y expresiva:

Así enamorado de la vida universal entra en la multitud como en un inmenso depósito de electricidad. Se le puede comparar también, a él, con un espejo tan inmenso como la multitud; a un caleidoscopio dotado de consciencia, que, en cada uno de sus movimientos, representa la vida múltiple y la gracia móvil de todos los elementos de la vida. Es un yo insaciable de no-yo, quien, a cada instante lo restituye y lo expresa en imágenes más vivas que la vida misma, siempre inestable y fugitivo (65).

Los ejemplos de esta posición subjetiva evocan los escenarios urbanos propuestos por Poe y, asimismo, los exóticos parajes, pero ahora, desde las nuevas relaciones de observación y participación que establece el flâneur. Baudelaire ya había avanzado esta fórmula en "Les Foules" [Multitudes] al

hombre vulgar... Se hagan llamar refinados, increíbles, bellos, leones o dandis, todos proceden de un mismo origen; todos participan del mismo carácter de oposición y de rebeldía; todos son representantes de lo que hay de mejor en el orgullo humano, de esa necesidad, demasiado rara entre los de hoy, de combatir y destruir la trivialidad... El dandismo es el último destello de heroísmo en las decadencias (Baudelaire, El pintor 92- 94). 
graficar la particular relación que establece al mundo, la figura que denominaba, por aquella época, le promeneur [el paseante]:

... solitario y pensativo saca una embriaguez singular de esta universal comunión. El que fácilmente se desposa con la muchedumbre, conoce goces febriles, del que estarán eternamente privados el egoísta, cerrado como un cofre, y el perezoso, interno como un molusco. Adopta como suyas todas las profesiones, todas las alegrías y todas las miserias que las circunstancias le presenta... inefable orgía, con esta santa prostitución del alma, que se da toda entera, poesía y caridad, a lo imprevisto que se revela, a lo desconocido que pasa (Baudelaire, Les Foules 34).

El día y la noche, puntos de fuga en el relato de Poe, son igualmente relevantes en el caso del pintor. Al describir la forma en que vivencia este ciclo, puntualizará que al despertar:

Admira la eterna belleza y la sorprendente armonía de la vida en las capitales, armonía tan providencialmente mantenida en el tumulto de la libertad humana. Contempla los paisajes de la gran ciudad, paisajes de piedras acariciadas por la bruma o las bofetadas del sol. Goza de las bellas tripulaciones, de los fieros caballos, de la limpieza deslumbrante de los botones, de la destreza de los lacayos, de los andares de las mujeres ondulantes, de los niños guapos, felices de vivir y de estar bien vestidos; en una palabra, de la vida universal" (Baudelaire, El pintor 65-66).

Y al anochecer:

El Sr. G. se quedará el último donde pueda resplandecer la luz, resonar la poesía, hormiguear la vida, vibrar la música; donde sea que una pasión pueda posar para su ojo, donde el hombre natural y el hombre convencional se muestren en una belleza bizarra, donde el sol ilumine las alegrías rápidas del animal depravado.... Todos los materiales de los que se ha atestado la memoria se clasifican, se alinean, se armonizan y experimentan esa idealización forzada que es el resultado de una percepción infantil, es decir, de una percepción aguda, ¡mágica a fuerza de ingenuidad! (Baudelaire, El pintor 67- 68).

Su apropiación del mundo incluirá destinos variados -Bulgaria, Turquía, Crimea, España- y motivos heterogéneos como la guerra, el comercio, la 
fiesta, la pompa de la vida. En la heterogeneidad de estos escenarios, su trazo expresa, simultáneamente, "el gesto y la actitud solemne o grotesca de los seres y su exposición luminosa en el espacio" (77).

Los rasgos más sobresalientes que el $S r$. $G$ manifiesta en sus viajes y en su activa imaginación llevan a refutar toda pretensión de reducir su búsqueda a la actividad de un mero paseante. Su exploración debe responder, necesariamente, a un fin elevado y general. Baudelaire concluirá que el $S r$. $G$. busca la modernidad, "pues no se presenta mejor palabra para expresar la idea en cuestión... Se trata, para él, de extraer de la moda lo que ella puede contener de poético en lo histórico, de sacar lo eterno de lo transitorio" (68).

Al profundizar en la comprensión de las posibles relaciones entre lo nuevo y lo antiguo, reafirmará el principio que encarna el pintor, para sostener que "La modernidad, es lo transitorio, lo fugitivo, lo contingente, la mitad del arte, cuya otra mitad es lo eterno y lo inmutable" (69). Lo inédito está enlazado, paradójicamente, con lo antiguo; su efecto novedoso supone una particular vinculación de lo familiar y lo desconocido.

Así, el $S r$ r. $G$, pintor de la vida moderna, permitirá a Baudelaire, no solo redefinir la particularidad del arte y lo bello, sino que también instalar un concepto inédito de modernidad que se transformará en un punto de referencia para pensar las nuevas manifestaciones humanas que tendrán lugar en las emergentes ciudades del siglo XIX. En este sentido, no resultaría aventurado sostener, como afirma Berman, que "Baudelaire nos muestra algo que ningún otro escritor ve tan bien: cómo la modernización de la ciudad inspira e impone a la vez la modernización de las almas de sus ciudadanos" (146). Sin embargo, cabría agregar que en esa empresa los aportes de Poe serán imprescindibles.

\section{CONCLUSIONES}

Al interpretar el valor y la relevancia que el relato "El hombre de la multitud" pudiese tener al interior de la obra de Edgar Allan Poe, es factible reconocer su significativo aporte al tratamiento de las problemáticas del doble, la detección y lo ominoso. Sin embargo, el cuento muestra, a su vez, un excepcional abordaje de la figura de la multitud y sus vinculaciones con los nuevos escenarios urbanos. En el flujo de sus desplazamientos, y mediante su particular mirada, el narrador personifica una nueva forma de habitar el espacio y el tiempo de la ciudad moderna. 
Si bien esta puede ser una novedad al interior de la obra de Poe, la influencia del cuento trascenderá los límites de su universo literario para transformarse en una referencia fundamental en el proyecto de reconceptualizar el arte moderno que emprenderá Baudelaire. En este sentido, es posible sostener que los principios que sustentan la obra "El pintor de la vida moderna" se corresponden nítidamente con los argumentos y los supuestos que definen al narrador figurado por Poe en su cuento sobre la multitud. El Sr. G, pintor de la vida moderna, resulta ser una encarnación perfecta del narrador de "El hombre de la multitud", en cuanto personifica sus rasgos más sobresalientes: convalecencia, anonimato, pasión por la multitud, flânerie. Ambos personajes hacen de la curiosidad su principio rector y de la urbe, su residencia. Sus individualidades, siempre abiertas a la circulación y al movimiento, mantienen un vínculo inédito con la multitud y la ciudad.

No se trata de una observación utilitaria o pragmática del paisaje metropolitano, sino más bien, de una mirada que se deja seducir por lo contingente y lo eterno, que busca lo bello, tensionando las relaciones entre lo clásico y lo contemporáneo, entre lo efímero y lo absoluto. En un caso, el narrador se sumerge en el entramado urbano tras la súbita y enigmática aparición del viejo en la multitud -lo que haría creer que se trata de una escena mundana y superficial- pero al mismo tiempo, se ve confrontado con preguntas que apelan a la esencia de la condición humana. Al igual que el hombre inmerso en la multitud, el pintor se entrega al mundo, pero no es un filósofo, ni un dandi, sino un artista que en su flânerie crea obras que intentan inscribir un fragmento inefable de lo humano.

En otras palabras, tanto el narrador anónimo de Poe, como el pintor de la vida moderna de Baudelaire, personifican la pasión irrefrenable por lo transitorio, lo fugitivo y lo contingente, elementos que anudados a lo eterno y lo absoluto, darán lugar a la definición paradigmática de lo moderno que harán de Baudelaire una figura crucial en las reflexiones sobre la modernidad.

\section{BIBLIOGRAFÍA}

Baudelaire, Charles. "Salon de 1846" (1846). Euvres Complètes Vol. 2. Curiosités esthétiques. Paris : Michel Lévy Frères, 1868. 77-198.

"Les Foules XII". Petits Poèmes en prose (Le spleen de Paris) (1861). Euvres Complètes. Ed. Jacques Crépet. Paris: Louis Conard, Libraire- Éditeur, 1926. 33-34.

"Le peintre de la vie moderne" (1863). Euvres Complètes. Vol 3. L'art romantique.

Paris: Michel Lévy Frères, 1885. 51-114. 

1906.

Lettres, 1841-1866: Portrait en héliogravure. Paris: Société du Mercure de France, Edgar Allan Poe. Trad. Carmen Santos. Madrid: La balsa de Medusa, 1988.

Benjamin, Walter. Libro de los pasajes. Ed. Rolf Tiedemann. Madrid: Akal Ediciones, 2004. Berman, Marshall. Todo lo sólido se desvanece en el aire: La experiencia de la modernidad. Trad. Andrea Morales. México: Siglo XXI, 1988.

Bonaparte, Marie. Edgar Poe: Eine Psychoanalytische Studie. Die Geschichten: der Zyklus Mutter. Wien: Internat. Psychoanalyt. Verl., 1934.

Brand, Dana. The spectator and the city in nineteenth-century American literature. Cambridge: Cambridge University Press, 1991.

Byer, Robert H. "Mysteries of the City: A Reading of Poe's «The Man of the Crowd»". Ideology and Classic American Literature. Eds. Sacvan Bercovitch and Myra Jehlen. N.Y.: Columbia Univ. Press, 1987. 221-246.

Cunningham, David. "El cuento de la modernidad: Poe, Benjamin y el relato de la metrópoli". La mala conciencia de la modernidad: Poe. Ed. Félix Duque. Trad. David Cruz. Madrid: Ediciones del CBA, 2009. 41- 78.

Elbert, Monika. "«The Man of the Crowd» and the Man outside the Crowd: Poe's Narrator and the Democratic Reader". Modern Language Studies 21, 4 (1991): 16-30.

Françon, Marcel. "Poe et Baudelaire". Publications of the Modern Language Association of America 60/ 3 (1945): 841- 859.

Frank, Frederick. S., y Magistrale, Anthony. The Poe encyclopedia. Wesport: Greenwood Press, 1997.

Freud, Sigmund. "Prólogo a Marie Bonaparte. Edgar Poe, Étude psychanalytique (1933)". Obras completas Sigmund Freud. V. XXII. Trad. José L. Etcheverry. Ed. James Strachey. Buenos Aires: Amorrortu, 1996. 229.

Frisby, David. Paisajes urbanos de la modernidad: Exploraciones críticas. Trad. Lilia Mosconi. Buenos Aires: Universidad Nacional de Quilmes, 2007.

Hayes, Kevin J. "Visual Culture and the Word in Edgar Allan Poe's «The Man of the Crowd»". Nineteenth-century Literature 56/ 4 (2002): 445-465.

Kennedy, Gerald J. “The Limits of Reason: Poe's Deluded Detectives”. American Literature 47/2 (1975): 184-96.

Levine, Stuart. "Poe and American Society". Canadian Review of American Studies 9/ 1(1978): 16-33.

Poe, Edgar Allan. "Berenice". Cuentos completos. Trad. Julio Cortázar. Ed. Fernando Iwasaki, Jorge Volpi. Madrid: Páginas de Espuma. 2009. 293-299.

“Morella”. Cuentos completos. Trad. Julio Cortázar. Ed. Fernando Iwasaki, Jorge Volpi. Madrid: Páginas de Espuma. 2009. 285- 289.

"Cuatro bestias en una. El hombre-camaleopardo". Cuentos completos. Trad. Julio Cortázar. Ed. Fernando Iwasaki, Jorge Volpi. Madrid: Páginas de Espuma. 2009. 869-878.

"Ligeia". Cuentos completos. Trad. Julio Cortázar. Ed. Fernando Iwasaki, Jorge Volpi. Madrid: Páginas de Espuma. 2009. 303-316. 
“La caída de la casa Usher”. Cuentos completos. Trad. Julio Cortázar. Ed. Fernando Iwasaki, Jorge Volpi. Madrid: Páginas de Espuma. 2009. 319-334.

."William Wilson”. Cuentos completos. Trad. Julio Cortázar. Ed. Fernando Iwasaki, Jorge Volpi. Madrid: Páginas de Espuma. 2009. 57-74.

"El hombre de la multitud". Cuentos completos. Trad. Julio Cortázar. Ed. Fernando Iwasaki, Jorge Volpi. Madrid: Páginas de Espuma. 2009. 247-254.

"La máscara de la Muerte Roja". Cuentos completos. Trad. Julio Cortázar. Ed. Fernando Iwasaki, Jorge Volpi. Madrid: Páginas de Espuma. 2009. 171-176.

"Un cuento de las montañas escabrosas". Cuentos completos. Trad. Julio Cortázar. Ed. Fernando Iwasaki, Jorge Volpi. Madrid: Páginas de Espuma. 2009. 179-187.

"The Philosophy of Composition". Graham's Magazine. 28/4 (1846): 163-167. The Edgar Allan Poe Society of Baltimore. <http://www.eapoe.org/works/essays/philcomp.htm>.

Ponzi, Mauro. "Ebriedad y terror. La multitud en Poe, Baudelaire y Benjamin". La mala conciencia de la modernidad: Poe. Ed. Félix Duque. Trad. Llanos Gómez. Madrid: Ediciones del CBA, 2009. 79-120.

Quinn, Patrick. "The Profundities of Edgar Poe”. Yale French Studies 6 (1950): 3-13.

The French Face of Edgar Allan Poe. Carbonale: Southern Illinois University Press, 1957.

Richard, Claude (Ed.). Edgar Allan Poe. Paris: Editions de l'Herne, 1998.

Sova, Dawn. B. Critical companion to Edgar Allan Poe: A literary reference to his life and work. New York: Facts on File, 2007.

Sweeney, Susan. E. “The Magnifying Glass: Spectacular Distance in Poe's «Man of the Crowd» and Beyond". Poe Studies/ Dark Romanticism. 36 (2003): 3-17.

Tester, Keith (Ed.). The Flâneur. London: Routledge, 1994.

Werner, James. American flâneur: The cosmic physiognomy of Edgar Allan Poe. New York: Routledge, 2004.

Yoswick, Thomas. "Moods of Mind: The Tales of Detection, Crime, and Punishment". A companion to Poe studies. Ed. Eric Carlson. Westport, Conn: Greenwood Press, 1996. 236-256. 